\title{
Mulheres, revoluções e missões
}

\author{
Graziela Schneider
}

Resumo: Dois meses depois da Revolução de Fevereiro de 1917, em que milhares de operárias decidem, no Dia das Mulheres, à revelia dos líderes bolcheviques, dar início a uma greve geral, Aleksándra Kollontai publica o texto "Nossas missões", no momento da efervescência do retorno da revista "Rabótnitsa". A tradução inédita, direta do russo, do referido texto, escrito por Kollontai no calor dos acontecimentos, tem o intuito de contribuir para recuperar, por meio da fonte primária, a voz da própria mulher russa revolucionária e lutar contra o seu apagamento na bistoriografia desse e de outros processos históricos.

Palavras-chave: Revolução Russa; Aleksandra Kollontai; Movimentos de mulheres; questão de mulheres; tradução

Аннотация: Через два месяуа после Февральской Револючии, когда тысячи женщин-работнии решили начать всеобшую забастовку в женский день вопреки решению большевистских лидеров, Александра Коллонтай опубликовала текст "Наши задачи", в момент возвращения к работе журнала "Работница". Прямой перевод с русского на португальский текста, написанного Коллонтай в разгар тех событий, призван помочь восстановить через первичный источник голос самой русккой женщины-револючионерки, а также противостоять умалчиванию её роли в историографии этого и других исторических прочессов.

КАючевые слова: Русская Револючия; Александра Коллонтай; Женское Авижение; женский вопрос; nеревод

Pouco tempo depois da Revolução de Fevereiro de 1917, em que milhares de operárias decidem, à revelia dos líderes bolcheviques, dar início a uma greve geral, Aleksándra Kollontai (Cf. nota 6) publica o texto "Nossas missões", no momento da efervescência do retorno da revista "Rabótnitsa"1.

1 “Operária". A revista começa a ser idealizada em 1913, por Inessa Armand (Choi Chatterjee, "Celebrating Women: Gender, Festival Culture, and Bolshevik Ideology, 1910-1939”, p. 30). Publicada pela "Izdátelstvo Pressa", a partir da iniciativa de mulheres, "Clements identifica a fundação da Rabótnitsa 
No dia da Mulher de 1917 (23 de fevereiro na Rússia, que seguia o calendário juliano), operárias têxteis conclamam mulheres e homens a protestos, que se intensificam e culminam na Revolução de Fevereiro. Para além do ato ao mesmo tempo concreto e simbólico, é importante compreender a participação das mulheres russas no processo revolucionário de forma mais amplificada, antes, durante e depois de Fevereiro e Outubro de 1917, e o seu protagonismo, que transcende a célebre manifestação do Dia da Mulher.

como o ponto em que o feminismo bolchevique emergiu" (Clements apud Scheide, Carmen, "Born in October': the Life and Thought of Aleksandra Vasil'evna Artyukhina, 1889-1969", in Melanie Ilič (ed.), "Women in the Stalin Era", Palgrave Macmillan, 2002, p. 14). Voltada, como o próprio nome alude, para operárias, o primeiro número "finalmente tem sua primeira edição, com tiragem de 12.000 cópias, em São Petersburgo, no Dia Internacional das Mulheres, em 1914. Entretanto, "Rabótnitsa" foi lançada apenas depois de quatro anos de debate sobre a necessidade de mulheres trabalhadoras terem mais do que uma "página de mulheres" no Pravda. Argumentando que a "questão da mulher" era apenas "um aspecto" da questão social geral, o POSDR, dominado por homens, opunha-se a uma publicação separada de mulheres, alegando que era um desperdício de fundos." (Jane Gary Harris, "Women’s Periodicals in Early Twentieth-Century Russia", in "Encyclopedia of Russian women's movements", Norma Corigliano Noonan and Carol Nechemias, ed., Greenwood Press, 2001, p. 113).

Apesar de ser atribuída a Lenin, há indícios, como cartas, de que a iniciativa da revista foi de mulheres, Inessa Armand, Nadiéjda Krúpskaia e Konkórdia Samóilova. Além das referidas revolucionárias, importantes nomes como Anna Elizárova, Liudmila Stal, Praskóvia Kudelli, Klávdia Nikolaiéva, Zlata Lilina, A. V. Artiúkhina, entre outras, faziam parte do conselho editorial e/ou participavam ativamente.

Ao longo de sua história, teve periodizações, tiragens e perfis variados, além de suspensões temporárias. Ainda em 1914, depois de apenas sete números, é obrigada a encerrar as atividades, devido a repressão policial, prisões e à I Guerra Mundial. Retomada somente em 1917, representa um instrumento de formação e conscientização, bem como um espaço para relatos de operárias sobre as condições de trabalho, as especificidades e divergências entre as suas demandas e as dos homens, o machismo, as diferenças, tanto no que diz respeito às próprias mulheres, que não formam um monólito, como entre os pensamentos e posicionamentos delas sobre questões políticas e práticas, de que forma e com o que atuavam, em geral, e, particularmente, na luta pela emancipação total das mulheres.

A partir da Guerra Civil, a edição é novamente interrompida, até 1923; posteriormente, passa a ser uma publicação do Jenotdiél, e, a partir da década de 1930, quando a questão da mulher é decretada, de forma unilateral e deliberada, resolvida, e o Jenotdiél impostamente fechado, seus contornos e sua temática passam por profundas mudanças.

Cf., entre outros, $\Lambda . Н$. Сталь, “История журнала “Работница”, в Печать и женское коммунистическое Авижение”, М., Госизаат, 1927 (L. N. Stal, "Istória jurnála Rabótnitsa”, v "Pechát i jénskoie kommunistítcheskoie dvijénie", M., Gossizdát, 1927); А.Ф Бессонова, "К истории издания журнала "Работница": Аокументы Института Маркса-Энгельса-Аенина-Сталина при ЦК КПСС”, 1955. С. 25-53. 1913-1914; ЦПА; (А. F. Bessanova, "K istórii izdánia jurnála "Rabótnitsa”: Dokumiénti Institúta Márksa-Éngelssa-Lénina-Stálina pri Ts. K. KPSS. S. 25-53. 1913-1914; TsPA, 1955); А^ександра В. Артюхина, “Первый женский рабочий журнал в России”, в ВсегАа с вами: сборник посвященный 50-летию журнала 'Работница', Иза. "Правла", М. 1964 (Aleksándra V. Artiúkhina, "Piérvi jénski rabótchi jurnál v Rossii', v Vsegdá s vámi: sbórnik posviaschénni 50-létiiu jurnála 'Rabótnitsa', Izd. "Pravda”, M., 1964); Rhonda Lebedev Clark,."Forgotten Voices: Women in Periodical Publishing of Late Imperial Russia, 1860-1905." Ph.D. Diss., University of Minnesota, 1996; Jehanne M. Gheith, e Barbara T. Norton (eds.), “An Improper 
Assim como a Revolução Russa não se iniciou em 1917, a produção e ação das russas remontam pelo menos ao século XIX, quando já concebiam escritos, instituições, eventos, periódicos. As mulheres sempre pensaram, escreveram, criaram, sempre atuaram em diversas arenas, sociais, culturais, artísticas, literárias, jornalísticas etc., sempre se organizaram, fizeram política, seja de forma declarada ou não, e suas obras e atos evidentemente não se restringiam à chamada jénski voprós (questão da mulher/de mulheres/feminina), nem apenas a temáticas relativas às suas próprias demandas.

É necessário, então, considerar o significado das mulheres russas no processo revolucionário como a de todas as mulheres de todas as épocas e lugares, em todos os momentos históricos e quotidianos: como essencial, seja nos protestos, seja nos combates, seja de forma direta, indireta, em suas lutas diárias, anônimas.

Dessa forma, é preciso reconhecer o envolvimento das mulheres nas revoluções russas não apenas como um lampejo, mas como parte de um histórico e contexto muito mais vastos e extensos no tempo e no espaço. Não foi apenas um ato extremado de necessidade devido às condições precarizadas, à miséria, à fome, não foi apenas por terra e por paz, não foi apenas pelo sufrágio universal, mas parte de um continuum, tanto em relação às revolucionárias predecessoras, da segunda metade do século XIX e início do XX, como de todas as mulheres que lutaram em defesa de sua emancipação, das mais variadas formas, e por meio das mais variadas armas, figuradas e físicas por palavras e protestos.

Um dos meios mais emblemáticos e imprescindíveis de enfrentamento, as greves - e, no caso das mulheres russas uma espécie de metonímia, embora incompleta, de seu protagonismo -, sobretudo as de 1905-07, 1912-1913, e as anteriores à de fevereiro de 1917, são uma das várias possíveis pistas para se traçar o percurso das revolucionárias ${ }^{2}$.

Profession: Women, Gender and Journalism in Late Imperial Russia”, Durham, NC, Duke University Press, 2001; R. C. Elwood, "Inessa Armand: Revolutionary and Feminist", Cambridge University Press, 2002; Валентина Ю. Смирнова, “Конструирование возраста в журнале "Работница” в советское время”, Женщина в российском обществе. 2016. № 1 (78). С.92-102. (Valentina Iu. Smírnova, “Konstruírovanie vozrásta v jurnále "Rabótnitsa" v soviétskoie vrémia", Jénschina v rossískom obschéstvie. 2016. № 1 (78). S.92-102.)

2 Cf. Steve Smith, Class and Gender: Women's Strikes in St. Petersburg, 1895-1917 and in Shanghai, 1895-1927, Social History, Vol. 19, No. 2 (May, 1994) p. 141-168, em especial as notas 16, 17 e 21, p. 144 e 145; na última, o autor faz menção à estimativa de outro pesquisador, Robert McKean, de que "houve 22 greves desse tipo, em 1912; 25, em 1913; 25, nos primeiros seis meses de 1914; 18, em 1915; 29, em 1916; e 8, nas primeiras sete semanas de 1917". 
Entretanto, para uma dimensão mais concreta do protagonismo das mulheres russas, tanto a respeito do processo revolucionário como um todo, quanto em relação a suas expressões e ações, diretas e indiretas, ao longo dos séculos XVIII ao XX, é necessário "redescobrir" e restaurar as fontes, o incontável material sobre elas, sobre suas questões, e, o mais importante, aquele produzido pelas próprias mulheres, com suas visões, vozes, palavras, posicionamentos.

A tradução direta do russo do referido texto, escrito por Kollontai no calor dos acontecimentos, tem o intuito de contribuir para recuperar a expressão da mulher russa revolucionária e lutar contra o seu apagamento ${ }^{3}$ na historiografia e nas referências bibliográficas desse e de outros processos históricos. ${ }^{4}$

3 A respeito do apagamento de mulheres russas, Cf, somente como alguns exemplos de muitos, e de inúmeros outros campos, inclusive a literatura e as artes em geral, Ann H. Koblitz, "Science, Women and the Russian Intelligentsia: The Generation of the 1860s", Isis, Vol. 79, № 2, Jun, 1988, p. 208-226; Olga Valkova, "The Conquest of Science: Women and Science in Russia, 1860-1960", in Michael Gordin et alli (ed.), "Intelligentsia Science: The Russian Century 1860-1960”, 2008, p. 136-165; Наталья $\Lambda$. Пушкарева, “Из небытия: женские имена в российской науке начала ХХ В.”, Научные ведомости Белгородского государственного университета. Серия: История. Политология. 2010. № 1 (72) (Natália L. Puchkarióva, “Iz nebitiá: jénskie imená v rossískoi naúke natchála XX V.”, Naútchnie vedómosti Belgoródskogo gossudárstvennogo universitéta. Séria: Istória. Politológuia. 2010. № 1 (72)); H. $\Lambda$. Пушкарева, “Женщины-историки в России 1810-1917 гг”, Вестн. Перм. ун-та. Сер. История. 2012. № 1 (18). C.228-245 (N. L. Puchkarióva, "Jénschini-istóriki v Rossíi 1810-1917 gg”, Vestn. Perm. un-ta. Ser. Istória. 2012. № 1 (18). S.228-245); Татьяна А. Минеева, "Письмо как форма коммуникации межАу научным сообществом и женщинами-историками во второй половине XIX начале XX в", Вестн. Перм. ун-та. Сер. История. 2012. № 1 (18). С.246-251 (Tatiána A. Minéieva, "Pismó kak fórma kommunikátsia méjdu naútchnim soobschéstvom i jénschinami-istórikami vo vtorói polovíne XIX natchále XX v", Vestn. Perm. un-ta. Ser. Istória. 2012. № 1 (18). S.246-251); Mary R. S. Creese, "Ladies in the Laboratory IV: Imperial Russia's Women in Science, 1800-1900. A Survey of their Contributions to Research", Rowman \& Littlefield, 2015.

4 Ainda hoje, tanto a historiografia como as referências bibliográficas gerais sobre mulheres e sobre mulheres e as revoluções russas, são, majoritariamente, de homens, apesar de existir ampla produção de mulheres sobre o tema, seja de fontes (embora haja poucas coletâneas, mesmo em russo ou em inglês), crítica ou pesquisa. Para citar apenas algumas, Cf. Надежда А. Карпецкая, "Работницы и Великий Октябрь”, ИзА-во Аенинградского университета, 1974 (Nadiéjda D. Karpétskaia, "Rabótnitsi i Velíki Oktiábr", Izd-vo Leningrádskogo universitéta, 1974); Barbara A. Engel, "The Emergence of Women Revolutionaries in Russia”, A Journal of Women Studies, Vol. 2, No 1, Spring 1977, p. 92-105.; B. C. Шакулова, “Культурная революция и женский вопрос", “Опыт КПСС в решении женского вопроса”, Отв. ред. Н. И. Кондакова, М., Мысль, 1981. - С. 77-102.. (V. S. Chakulóva, "Kultúrnaia revoliútsia i jénski voprós", "Ópit KPSS v rechénii jénskogo vopróssa”, Otv. red. N. I. Kondakova, M., Mísl, 1981. S. 77-102.); Rose L. Glickman, "Russian Factory Women: Workplace and Society, 1880-1914”, Berkeley and Los Angeles: University of California Press, 1984; Cathy Porter, "Women in Revolutionary Russia”, Cambridge, Cambridge University Press, 1987; Christine Johansson, "Women's Struggle for Higher Education in Russia, 1855-1900”, Mc-Gill-Queen’s University Press, 1987; ЭАеонора А. Павцюченко, “Женщины в русском освободительном движении: от Марии Волконской до Веры Фигнер”, Мысль, 1988 (Eleonora A. Pavliútchenko, Jénschini v rússkom osvobodítelnom dvijéni: ot Maríi Volkónskoi do 


\section{Наши задачи}

Большая, ответственная, серьезная задача стоит сейчас перед работницами и рабочими нашей страны. Надо построить “новую Россию”, такую Россию, гАе рабочему цюАу, гАе наемнослужащим, прислуге, поденщикам, работницам иглы и просто женам рабочих жилось бы Аучше и светлее, чем жилось при проклятой памяти царствования Николая Кровавого.

Но мало того, что переА рабочими и работницами России сейчас стоит задача завоевать и закрепить за пролетариатом, за мелкими крестьянами власть в государстве и провести, установить такие порядки, чтобы ограничить аппетиты выжимателей-капиталистов, охранить интересы трудящихся. Пролетариат России сейчас находится в особом положении по сравнению с рабочими и работницами Аругих стран.

Великая российская революция поставила нас, русских работниц и рабочих, в первые ряды борцов за общемировое, рабочее дело, за общерабочие интересы.

Мы можем свободнее говорить, писать и действовать, чем работницы и рабочие Аругих стран.

Как же не использовать нам эту свободу, завоеванную кровью наших товарищей, Аля того чтобы теперь, не меАля, сосредоточить наши силы, силы

Véri Figner, Mísl, 1988); Marie-Claude Burnet-Vigniel, "Femmes russes dans le combat revolutionnaire", Institut d'études slaves, Paris, 1990; Barbara E. Clements, "Bolshevik women”, Cambridge, CUP, 1997; B. A. Engel, "Not by Bread Alone: Subsistence Riots in Russia during World War I", The Journal of Modern History 69, December 1997, p. 696-721; Наталья П. Рушанина, “Женский вопрос в России и основные подходы к его изучению в дореволюционный период”, Magistra Vitae: электронный журнал по историческим наукам и археологии. 1999. № 2 (10). C.77-87 (Natália P. Ruchanina, "Jénski voprós v Rossíi i osnóvnie podkhódi k ego izutchéniu v dorrevoliutiónni períod”, Magistra Vitae: elektróni jurnál po istorítcheskim naúkam i arkheológui. 1999. № 2 (10). S.77-87); Jane McDermid, "Midwives of the revolution: female Bolsheviks and women workers in 1917”, London, UCL Press, 1999; Anna Hillyar; Jane McDermid (ed.), "Revolutionary Women in Russia, 1870-1917: A Study in Collective Biography", Manchester, Manchester University Press, 2000; Rochelle G. Ruthchild, “Equality \& Revolution: Women's Rights in the Russian Empire, 1905-1917”, Pittsburgh: University of Pittsburgh Press, 2010; Моника И. Старуш, “К истории “Женского вопроса” в СССР в первые постреволюционные годы”, Вестник МГУКИ, № 5, 2011, С.59-64 (Mónika I. Staruch, "K istórii “Jénskogo vopróssa” v SSSR v pérvie postrevoliutsiónnie gódi”, Véstnik MGUKI, № 5, 2011, S.59-64); Aino Saarinen; Kirsti Ekonen; Valentina Uspenskaia (eds.), "Women and Transformation in Russia", Nova Iorque, Routledge, 2014; Marianna Muravyeva; Natalia Novikova (eds), "Women's History in Russia: (Re)Establishing the Field", Newcastle upon Tyne, Cambridge Scholars Publishing, 2014, Erin K. Krafft, "Reading Revolution in Russian Women's Writing: Radical Theories, Practical Action, and Bodies at Work”, Phd. Dissertation, Brown University, Providence, Rhode Island, 2015. 
женщин рабочего класса, и повести неустанную, настойчивую массовую борьбу за скорейшее окончание мировой бойни?

Наши товарки, работницы Аругих стран, жАут от нас этого шага.

Война сейчас — самое страшное зАо, которое тяготеет наА нами. Пока война не кончена, не построить нам новой России, не разрешить вопроса о хлебе, о продовольствии, не одолеть дороговизны. Пока война каждый час убивает, калечит наших детей и мужей, нет покоя нам, женщинам рабочего кАасcа!..

Если наша первая задача — помочь нашим товарищам построить новую демократическую Россию, то вторая, не менее назревшая и более близкая наша задача, - поднять работниц Аля войны с войной.

А это значит: во-первых, не только самой понять, что это не наша война, что ведется она во имя карманных интересов толстосумов-хозяев, банкиров, фабрикантов, но и постоянно разъяснять это товарищам работницам и рабочим.

Во-вторых, это значит: сплачивать силы работниц и рабочих вокруг той партии, которая не только защищает интересы пролетариата России, но

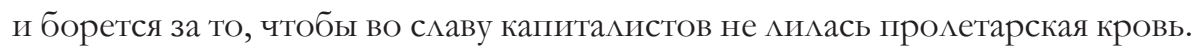

Товарищи работницы, нет больше наших сил мириться с войной, с Аороговизной! Надо бороться! ИАите в наши ряды, в ряды социацАемократической рабочей партии! Но мало сорганизоваться в партию. Если мы Аействительно хотим ускорить мир, наАо, чтобы рабочие и работницы пове и борьбу за то, чтобы власть в государстве перешла бы из рук крупных капиталистов, истинных виновников всех наших слез, всей крови, что мьется на полях битвы, в руки представителей наших — в Совет рабочих и солдатских депутатов.

В борьбе с войной и Аороговизной, в борьбе за то, чтобы закрепить в $а$ асть в России за неимущими, за трудящимися, в борьбе за новые порядки и законы, многое зависит от нас, от работниц. Прошло то время, когда успех рабочего дела решался только организованностью мужчин. Теперь, с этой войной, произошла резкая перемена в положении женщин рабочего класса. Женский труд встречается теперь повсюду. Война заставила работниц взяться за работу, о которой раньше они и не помышляли. Если в 1912 году на 100 мужчин на фабриках, на заводах приходилось 45 женщин, то теперь нередко бывает, что на 75 рабочих насчитывается 100 работниц.

Успех рабочего дела, успех борьбы рабочих за лучшую жизнь: за более короткий день, за более высокую плату, за страхование на случай болезни, 
безработицы, старости и т. А., за защиту труда наших детей, за мучшие школы - зависит теперь не только от сознательности и организованности мужчин, но и от того, сколько нас, работниц, войдет в ряды организованного рабочего класса. Чем больше нас булет в рялах организованных борцов за наше общее рабочее дело и за наши рабочие нужды, тем скорее мы добьемся уступок от капитацистов-выжимателей.

В организованности вся наша сила, вся наша надежда!

Наш клич Аолжен быть сейчас: товарищи работницы!

Не стойте в одиночку! В одиночку мы — соломинка, которую всякий хозяин согнет. Организованные, мы - великая сила, которую никто сломить не может.

Мы, работницы, первые в Ани русской революции подняли Красное знамя, мы первые в Женский день вышли на улицу61. Поспешим же и сейчас в первые ряды борцов за рабочее дело, илем в профессиональные союзы, в социалдемократическую партию, в Совет рабочих и солАатских Аепутатов!

Будем добиваться сплоченными рядами скорейшего окончания бойни народов, будем бороться со всеми, кто забыл великий завет рабочего мюда о еАинении, о солидарности рабочих всех стран.

Только в революционной борьбе против капиталистов всех стран и только в единении с работницами и рабочими всего мира мы завоюем новое светлое будущее - социалистическое братство рабочих.

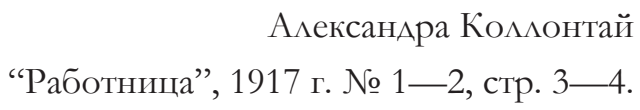

\section{Nossas missões ${ }^{5}$}

Há uma grandiosa missão, crucial, séria, diante das trabalhadoras e trabalhadores do nosso país. É necessário construir uma "nova Rússia”, uma Rússia onde as pessoas trabalhadoras, onde os empregados assalariados, as empregadas domésticas, os temporários, as costureiras e simplesmente as esposas dos ope-

5 Publicado pela primeira vez em Работница (Rabótnitsa), 10 maio de 1917. № 1-2, p. 3-4. 
rários viveriam melhor e de forma mais promissora do que viviam sob a maldita memória do reinado de Nikolai, o Sanguinário.

Mas, diante dos operários e operárias da Rússia não há agora apenas a missão de conquistar e consolidar o poder estatal pelo proletariado e pelos pequenos agricultores, de introduzir e instaurar normas para limitar as ambições dos capitalistas exploradores, e de defender os interesses da classe trabalhadora. $\mathrm{O}$ proletariado da Rússia se encontra agora em uma posição especial em comparação com os operários e operárias de outros países.

A grande revolução russa nos colocou, operárias e operários russos, nas primeiras filas dos combatentes por uma causa operária, universal, pelos interesses dos operários em geral.

Podemos falar, escrever e agir com mais liberdade do que as operárias e operários de outros países.

Como não usar essa liberdade, conquistada pelo sangue de nossos camaradas, para, neste momento, sem perder tempo, concentrar nossas forças, as forças das mulheres da classe operária, e conduzir uma luta das massas, incansável, persistente, pelo fim, o mais rápido possível, do massacre mundial?

Nossas camaradas, operárias de outros países, esperam de nós esse passo.

A guerra é agora o mal mais terrível que gravita sobre nós. Enquanto a guerra não acabar, não poderemos construir uma nova Rússia, não será resolvida a questão do pão, da comida, não será superada a carestia. Enquanto a guerra matar a cada hora, mutilar nossos filhos e maridos, não haverá paz para nós, mulheres da classe operária!

Se a nossa primeira missão é ajudar nossos companheiros a construir uma nova Rússia democrática, então a nossa segunda missão, não menos urgente, e sim mais iminente, é alçar as operárias para a guerra contra a guerra.

E isso significa: primeiro, não apenas entender por nós mesmas que esta não é nossa guerra, que ela é conduzida em nome dos interesses dos bolsos dos patrões ricaços, banqueiros, industriais, mas também explicar isso a camaradas operárias e operários incessantemente.

Segundo, isso significa: unir as forças das operárias e operários em torno do partido que não só defende os interesses do proletariado da Rússia, mas também luta para que o sangue proletário não seja derramado para a glória dos capitalistas.

Camaradas operárias, não temos mais forças para nos resignarmos com a guerra, com a carestia! Devemos lutar! Vocês devem ir para as nossas fileiras, para as fileiras do Partido Operário Social Democrata! Mas não basta se organizar no 
partido. Se quisermos realmente antecipar a paz, os operários e operárias devem conduzir a luta para que o poder estatal passe das mãos dos grandes capitalistas, os verdadeiros culpados de todas as nossas lágrimas, de todo o sangue que é derramado nos campos de batalha, para as mãos de nossos delegados - para o Soviete de Deputados Operários e Soldados.

$\mathrm{Na}$ luta contra a guerra e a carestia, na luta para se consolidar o poder na Rússia pelos desprovidos, pelos trabalhadores, na luta por novas normas e leis, muito depende de nós, das operárias. Já passou o tempo em que o êxito da causa operária era decidido apenas pela capacidade de organização dos homens. Neste momento, contra essa guerra, houve uma transformação profunda na situação de mulheres da classe operária. O trabalho feminino agora é visto por toda parte. A guerra obrigou as operárias a começar a trabalhar com algo que nunca haviam pensado antes. Se, em 1912, havia 45 mulheres para cada 100 homens nas fábricas, neste momento não é raro que haja 100 operárias para cada 75 operários.

O êxito da causa operária, o êxito da luta dos operários por uma vida melhor: por menos horas de trabalho, por um salário mais alto, por seguro em caso de doença, desemprego, idade avançada etc., pela proteção contra o trabalho de nossas crianças, por melhores escolas - depende neste momento não apenas da consciência e da capacidade de organização dos homens, mas também de quanto nós, operárias, ingressaremos nas fileiras da classe operária organizada. Quanto mais estivermos nas fileiras dos combatentes organizados por nossa causa operária comum e por nossas demandas operárias, mais cedo obteremos concessões dos exploradores capitalistas.

$\mathrm{Na}$ capacidade de se organizar está toda a nossa força, toda a nossa esperança!

Nosso brado agora deve ser: camaradas operárias!

Não fiquem sozinhas! Sozinhas, nós somos como um graveto, que qualquer patrão despedaça. Organizadas, nós somos uma força muito grande que ninguém pode quebrar.

Nós, operárias, fomos as primeiras a erguer a Bandeira vermelha nos dias da revolução russa, fomos as primeiras a ir para a rua, no Dia da Mulher. Vamos nos precipitar também agora para as primeiras fileiras dos combatentes pela causa operária, vamos para os sindicatos, para o Partido Social-Democrata, para o Soviete de Deputados Operários e Soldados!

Vamos obter por meio das fileiras unidas o fim, o quanto antes, do massacre dos povos, lutaremos contra todos os que esqueceram a grande aliança da multidão de operários pela união, pela solidariedade dos operários de todos os países. 
Somente na luta revolucionária contra os capitalistas de todos os países e somente na união com as operárias e operários de todo o mundo conquistaremos um futuro novo e promissor - a fraternidade socialista dos operários.

\author{
Aleksandra Kollontai ${ }^{6}$ \\ Rabótnitsa, 1917. № 1-2, p. 3-4.
}

6 Aleksándra Mikháilovna Kollontai (1872-1952), possivelmente a revolucionária russo-soviética mais célebre e mais traduzida, lida e pesquisada no Ocidente, também foi escritora, jornalista e política. Reunida em mais de 10 tomos, sua obra inclui artigos, ensaios, memórias e ficção, sobretudo a respeito da emancipação da mulher. No Brasil, começa a ser traduzida, indiretamente, a partir de 1958.

De família aristocrática, nasce em São Petersburgo. Filia-se ao Partido Operário Social-Democrata Russo, em 1899; entre 1901 e 1903 vai para a Europa Ocidental. Ao retornar para a Rússia, participa da Revolução de 1905; devido a uma publicação polêmica, é forçada a se exilar, novamente na Europa Ocidental, entre 1908 e 1917, e continua atuando em várias atividades políticas, aproximando e distanciando-se tanto dos mencheviques como dos bolcheviques, até 1915, quando ingressa de forma mais categórica no Partido Bolchevique. Na Revolução de Fevereiro ainda se encontra fora da Rússia; quando retorna, participa ativamente de todo o processo revolucionário, ao longo de 1917, com discursos, textos, como delegada em congressos, organizando greves etc. Depois da revolução de Outubro, foi a primeira mulher a atuar no governo soviético, como comissária de Assistência Social, trabalhando em especial com políticas relativas às questões das mulheres e sua concretização não apenas jurídica, mas na esfera cotidiana. Em 1919 ajuda a instituir, com Inessa Armand, o Jenotdiél - Jénski Otdiél - o Departamento ou Seção de Mulheres do Comitê Central do Partido Comunista da URSS. Participou do conselho editorial da "Rabótnitsa" e da "Komunístka". Em 1921, coopera na fundação da Oposição Operária. Foi embaixadora na Noruega (1923-1926; 1927-1930), México (1926-1927) e Suécia (1930-1945), a primeira mulher da URSS e a segunda da história. Falece em 1952, em Moscou.

Cf., entre outros, А. М. Иткина, “Революционер, трибун, Аипломат: Страницы жизни А. М. Колєонтай”, М.: Политиздат, 1970. (А. M. Itkina, "Revoliutsionér, tribún, diplomát: Stranítsi jízni A. M. Kollontái", M.: Politizdát, 1970); B. Evans Clements, "Bolshevik Feminist: The Life of Aleksandra Kollontai", Bloomington e London: Indiana University Press, 1979; Beatrice Farnsworth, "Aleksandra Kollontai: Socialism, Feminism, and the Bolshevik Revolution”, Stanford, CA, Stanford University Press, 1980; B. Williams, "Kollontai and After: Women in the Russian Revolution", in S. Reynolds (ed.), "Women, State and Revolution: Essays on Power and Gender in Europe since 1789", Brighton, 1986, p. 65-6.; Cathy Porter, “Alexandra Kollontai: A Biography”, London, Virago, 1980; 3. С. Шейнис, “Путь к вершине: Страницы жизни А. М. Комлонтай”, М.: Сов. Россия, 1987. (Z. S. Cheinis, "Put k verchíne: Strabítsi jízni A. M. Kollontái”, M.: Sov. Rossía, 1987); Norma C. Noonan, “Two Solutions to the Zhenskii Vopros in Russia and the USSR - Kollontai and Krupskaia: A Comparison.”, Women and Politics 11, no. 3, 1991, p. 77-99; Norma Corigliano Noonan e Carol Nechemias (ed.), "Encyclopedia of Russian women's movements”, Greenwood Press, 2001, p. 142-144; Тимо Вихавайнена е Евгения Хейсканена, “Александра Комлонтай и Финляндия.”. Перевод с финского на русский: Евгений Хейсканен. Renvall Institute Publications 29. Hakupaino Oy. Helsinki, 2010. (Timo Vikhavainena i Evguenia Kheiskanena, “Aleksandra Kollontái i Finliándia”. Perevód s fínskogo na rússki: Evgueni Kheiskanen. Renvall Institute Publications 29. Hakupaino Oy. Helsinki, 2010.); Ирина И. Юкина, "На пути к марксистскому феминизму. Аеятельность Александры Колмонтай” (Irína I. Ipukina, “Na púti k marksístskomu feminízmu. Deiátelnost Aleksándri Kollontái”), in Sociology of Science and Technology, Volume 5, No. 2, 2014. 


\section{Referências}

CHATTERJEE, Choi. Celebrating Women: Gender, Festival Culture, and Bolshevik Ideology, 19101939, University of Pittsburgh Press, 2002, p. 30.

HARRIS, Jane Gary. "Women's Periodicals in Early Twentieth-Century Russia”, in Encyclopedia of Russian women's movements, Norma Corigliano Noonan and Carol Nechemias (ed.), Greenwood Press, 2001, p. 113.

KOLLONTAI, A. M. Наши задачи. "Работница", 1917 г. № 1-2, стр. 3-4. (Náchi Zadátchi. "Rabótnitsa”, 1917. № 1-2, p. 3-4).

NOONAN, Norma Corigliano. "Kollontai, Aleksandra Mikhailovna (1872-1952)", in Encyclopedia of Russian women's movements, Norma Corigliano Noonan and Carol Nechemias, ed., Greenwood Press, 2001, p. 142-144.

SCHEIDE, Carmen. 'Born in October': the Life and Thought of Aleksandra Vasil'evna Artyukhina, 1889-1969, in Ilič, Melanie (ed.). "Women in the Stalin Era", Palgrave Macmillan, 2002, p. 14.

SMITH, Steve. Class and Gender: Women's Strikes in St. Petersburg, 1895-1917 and in Shanghai, 1895-1927. “Social History”, Vol. 19, No. 2 (May, 1994) p. 141-168. 